\title{
Communication
}

Stephen Dance* and Lindsay McIntyre

\section{The Quiet Project - UK Acoustic Community's response to COVID19 during the easing of lockdown}

https://doi.org/10.1515/noise-2021-0003

Received Jul 05, 2020; accepted Nov 18, 2020

\begin{abstract}
The COVID-19 lockdown created a new kind of environment both in the UK and globally, never experienced before or likely to occur again. A vital and timecritical working group was formed with the aim of gathering crowd-source high quality baseline noise levels and other supporting information across the UK during the lockdown and subsequent periods. The acoustic community were mobilised through existing networks engaging private companies, public organisations and academics to gather data in accessible places. In addition, pre-existing on-going measurements from major infrastructure projects, airport, and planning applications were gathered to create the largest possible databank. A website was designed and developed to advertise the project, provide instructions and to formalise the uploading of noise data, observations and soundscape feedback. Two case studies gathered in the latter stage of full lockdown are presented in the paper to illustrate the changes in the environmental noise conditions relative to transport activity. Ultimately the databank will be used to establish the relation to other impacts such as air quality, air traffic, economic, and health and wellbeing. As publicly funded research the databank will be made publicly available to assist future research.
\end{abstract}

Keywords: noise, transport, soundscape, crowd-source

\section{Introduction}

The COVID-19 lockdown has created a new kind of environment both in the UK and globally never experienced before or likely to occur again. The Quiet Project was conceived by the realisation that environmental noise levels had changed dramatically as communities across the coun-

\footnotetext{
${ }^{\star}$ Corresponding Author: Stephen Dance: Acoustics Group, School of the Built Environment and Architecture, London South Bank University, Borough Road, London SE1 0AA; Email: dances@lsbu.ac.uk Lindsay McIntyre: KSG Acoustics, Glasgow, Scotland
}

ə Open Access. (C) 2021 S. Dance and and L. McIntyre, published by De Gruyter. Attribution 4.0 License try followed the UK Government's advice to "Stay home" and later to "Stay safe".

The first COVID-19 outbreak occurred on $17^{\text {th }}$ November 2019 and arrived in the UK on $29^{\text {th }}$ January 2020. The UK Lockdown occurred on $23^{\text {rd }}$ March 2020. Hence, the Quiet Project was setup on $6^{\text {th }}$ April 2020 as a time-critical data gathering respond to collect and collate baseline noise data at hundreds of locations across the nation during the unprecedented COVID-19 Lockdown; Table 1 shows the time line of the UK outbreak, Government advice and alert level. Of course, Lockdown effected road, rail, aviation, commence and industry but this paper is focused solely on road traffic.

Previously long-term studies have been undertaken by permanent monitoring in Madrid, Rome, Paris, Milan, and Rotterdam [1-5]. These projects were used to assess and validate noise mapping software, or to compare mobile vs static noise measure solutions across major cities. The UK currently has no permanent city-based high-quality monitoring installation and therefore was acoustically underprepared for the outbreak. If such a system was available, then the noise evolution during Lockdown could have easily been monitored on a city scale. However, the situation provided the impetus and the opportunity for the first time to create a project to survey the entire country. This obviously had the advantage over previous city-based studies of considering the effect of a national lockdown on an entire country.

Development of the survey required a rapid response which was only possible due to the acoustic community's willingness to participate to deliver what would be called the Quiet Project [6]. A working party was immediately formed comprising of consultants, government agencies, and academics. This working group defined the scope of the data to be gathered and, with the endorsement of the Institute of Acoustics [7], Association of Noise Consultants [8], Noise Abatement Society [9] and UK Acoustics Network (UKAN) [10], a network of acoustic professionals was mobilised in record time. 
Table 1: Lockdown status of England

\begin{tabular}{|c|c|c|c|c|c|c|c|c|c|c|}
\hline & $\begin{array}{c}17 \text { Nov } \\
2019\end{array}$ & $\begin{array}{c}29 \text { Jan } \\
2020\end{array}$ & $\begin{array}{c}23 \text { March } \\
2020\end{array}$ & $\begin{array}{c}11 \text { May } \\
2020\end{array}$ & $\begin{array}{l}1 \text { June } \\
2020\end{array}$ & $\begin{array}{c}15 \text { June } \\
2020\end{array}$ & $\begin{array}{c}19 \text { June } \\
2020\end{array}$ & $\begin{array}{l}4 \text { July } \\
2020\end{array}$ & $\begin{array}{c}150 c t \\
2020\end{array}$ & $\begin{array}{l}5 \mathrm{Nov} \\
2020\end{array}$ \\
\hline Event & $\begin{array}{c}\text { 1st } \\
\text { Case in } \\
\text { the } \\
\text { World }\end{array}$ & $\begin{array}{l}1^{\text {st }} \mathrm{UK} \\
\text { Case }\end{array}$ & $\begin{array}{c}\text { Lockdown } \\
\text { Starts }\end{array}$ & Easing & $\begin{array}{c}\text { Schools } \\
\text { reopen for } \\
\text { Year } 5 \text { and } \\
10\end{array}$ & $\begin{array}{c}\text { Non- } \\
\text { essential } \\
\text { shops } \\
\text { open }\end{array}$ & $\begin{array}{l}\text { Football } \\
\text { restarts } \\
\text { without } \\
\text { crowds }\end{array}$ & $\begin{array}{c}\text { Restaurants } \\
\text { / Pubs } \\
\text { reopen }\end{array}$ & $\begin{array}{l}\text { Multi-Tier } \\
\text { Regional } \\
\text { Lockdown }\end{array}$ & $\begin{array}{l}\text { Lockdown } \\
\text { except for } \\
\text { education }\end{array}$ \\
\hline Status & $\begin{array}{c}\text { Level } 1 \\
\text { Normal } \\
\text { Life }\end{array}$ & $\begin{array}{c}\text { Level } 1 \\
\text { Normal } \\
\text { Life }\end{array}$ & $\begin{array}{c}\text { Level } 4 \\
\text { Stay at } \\
\text { Home }\end{array}$ & $\begin{array}{c}\text { Level } 4 \\
\text { Stay } \\
\text { Alert }\end{array}$ & $\begin{array}{l}\text { Level } 4 \\
\text { Stay Alert }\end{array}$ & $\begin{array}{l}\text { Level } 4 \\
\text { Stay Alert }\end{array}$ & $\begin{array}{c}\text { Level } 3 \\
\text { Stay } \\
\text { Alert }\end{array}$ & $\begin{array}{c}\text { Level } 3 \\
\text { Stay Alert }\end{array}$ & $\begin{array}{c}\text { Level } 4 \\
\text { Hands } \\
\text { Face } \\
\text { Space }\end{array}$ & $\begin{array}{c}\text { Level } 4 \\
\text { Stay at } \\
\text { Home }\end{array}$ \\
\hline
\end{tabular}

\section{Methodology}

The working party quickly decided that crowd sourcing was the most appropriate method to collect robust highquality acoustic data and observations. This was necessary as crowd sourcing data collection without experience of acoustic instrumentation would be unwise, due to issue of increased uncertainty. The use of the Soundprint App was briefly considered, with the author kindly adding different types of outdoor spaces to the software. This software was originally written to measure restaurant noise levels and hence included no wind reduction mitigation [11]. A critical consideration for environmental noise measurements. On a positive note Soundprint could automatically geo-locate measurement positions. However, the quality of the iPhone cannot be guaranteed, as the measurement chain was uncalibrated. Finally, the smartphone approach does have one advantage, the number of data points that could be collected. On balance it was decided that quality of data was more important, and the smartphone option was dismissed.

The working party decided the best strategy was to utilise the large number of employees in acoustics who were furloughed across the UK during Lockdown. This provided the opportunity to utilise their expertise and spare time to undertake measurements and observations. The UK position on furlough was that every employee, employed at the end of February 2020 would be paid $80 \%$ of their wage, up to $£ 2500$ per month by the UK Government. The key proviso was they could not undertake any work for their employer. Furloughed employees could still work, but only for a different company. Hence, these consultants were familiar with the instrumentation and could take acoustic measurements for the Quiet Project (unpaid) without jeopardizing their financial support. The impact of COVID19 on the acoustics industry has been recently documented by a survey of over 200 UK acoustics companies by Lincoln [12].
This work was also funded by the UK Acoustics Network (UKAN).

The immediate issue for the Quiet Project was the immediacy of Lockdown. This left acoustic instrumentation in locations not readily available. This issue was solved by contacting key acoustic suppliers who had instrumentation that could not be utilised on contracted sites. These suppliers agreed that the acoustic instrumentation could be hired for free. UKAN agreed to cover the shipping costs of the instrumentation to the furloughed employees across the UK, but only if they were on the contact list of the acoustic suppliers. This was agreed for reasons of reassurance on quality and insurance purposes. In addition, consultants with their own acoustics instrumentation were asked to help take measurements using the Institute of Acoustics weekly Zoom meetings.

Once the instrumentation was organised a pamphlet was produced which outlined how the measurements were to be taken, of course it was critical that all equipment was handled in line with government safety guidance. Hence only locations on property where explicit permission had been granted were used for the study.

A website was designed and developed in early April 2020 to advertise the project, providing instructions to the volunteers, and to supply the templates for data formatting and observations as well as hosting the databank as it grows. As a publicly funded project it was agreed to make the data available whilst providing assurances as regards data protection and GDPR legislation.

For the measurements calibrated and certified Class 1 or Class 2 noise monitoring equipment [13] was to be used. The measurement should be for a period of at least one week and preferably longer in accordance with BS7445 [14]. A longer survey with good quality supporting information would minimise sources of potential uncertainty. The participants signed up to repeat the measurements at six monthly intervals to track the recovery or a second lockdown. 
In addition, on-going data collection from major infrastructure works such as construction projects, airports, and other commercial entities such as planning applications were contacted. These projects have networks of long-term environmental sound monitoring locations, for example HS2, UK Airports and Thames Tideway. A letter was written to each of these organisations with assurances as regards use of the data and anonymisation of the noise data using statistics. Progress with this approach has been slow as employees of these infrastructure companies were also furloughed.

Finally, acoustic related UK news items in the media were gathered to provide further evidence of the environmental impact of the lockdown. This culminated in October 2020 with the Quiet Project contributing to a Natural History Museum Exhibition "Nature liberated by Lockdown" [15].

\section{Data collection}

It was decided by the working group that noise measurements should be made at 15-minute intervals, starting on the hour. This approach matched the transportation data collected in the UK by Highways England [16]. Acoustic parameters measured included: LAeq, LAMax, LA10 and LA90. This is in line with measurements taken as part of a BS4142:2014 environmental noise assessment [17]. In addition, optional spectral data would be collected in either octave or $1 / 3$ octave bands. This data was to be formatted using the supplied Excel template which also included location description, GPS position, free field condition, measurement height, as well as time and date information.

In addition, a writeable PDF observation sheet was produced. This PDF included contact details, instrumentation details, calibration information, location description selection, the normal primary noise source, a note section to include daily weather observations such as wind speed, wind direction, temperature, and precipitation. This information would allow the noise data to be edited for outliers and be useful for computer modelling and verification purposes. Outliers could be for unexpected sound source such as fireworks, parties, etc.

Finally, during the upload process, participants were asked to complete a series of dropdown soundscape questions. These have been adapted from Questionnaire (Method (A) of Annex C3 ISO / TS 12913-2: 2018 [18].

The questions focused on the kind of location at which the measurements were taken, types of sound sources heard, context of the sound being heard, and qualitative rating of the sound environment plus the appropriateness of the sound environment. Completion of the questions unlocks the ability to upload the participant's results to ensure that the soundscape data is collected relevant to each location. Identification of other potential sources of uncertainty such as temporary sounds e.g. agricultural machinery operation details allowed the elimination of invalid data from the dataset.

The last step is an optional procedure to upload supporting information including photographs of the measurement environment as well as short audio clips to illustrate the aural environment for later Soundscape analysis. For example, Figure 1 shows an inner-city measurement location under unusually good weather conditions. These astonishing stable weather conditions existed across the UK during Lockdown, early April to early June 2020.

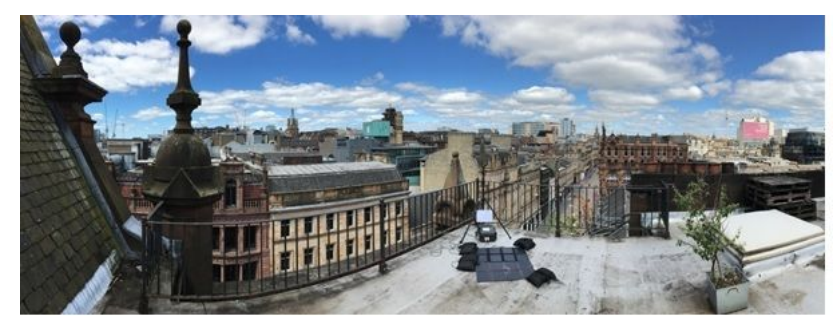

Figure 1: Glasgow City Centre monitoring location

\section{Initial results}

The website now has over 120 individual user accounts, as of $5^{\text {th }}$ November 2020. Each user may have more than one location at which measurements have been taken hence it is believed that 300 locations across the UK have been measured, see Figure 2, creating over 1000 weeks of highquality data.

Initial analysis combined the data to create day (07:0019:00), evening (19:00-23:00) and night (23:00-07:00) as used in EU Noise Mapping. The longitundal noise measurements for two case studies: one a tranquil rural location (major source A12) and one next to a major trunk road (major source A120) were undertaken at the moment of maximum easing of Lockdown in the UK, see Table 1, late May to mid-June 2020, when the schools reopened.

To determine the average LAeq traditional equal continuous energy calculations were undertaken in Excel over the day, evening, night durations. However, for the statistical acoustic parameters, LA10 and LA90 a different approach was necessary. The median value for each parameter over 


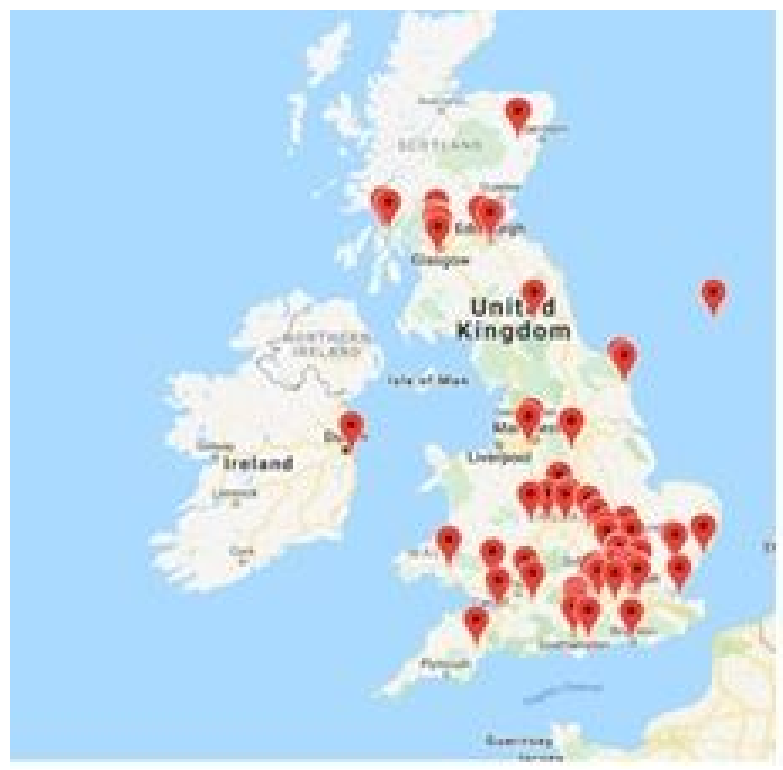

Figure 2: Location of Quiet Project Monitoring stations, as of $15^{\text {th }}$ June 2020

each duration was calculated to give the average value. This is the recommended analysis methodology used in a BS4142:2014 assessment [17]. The averages were determined from 48 day-time measurements, 16 evening measurements and 32 night-time measurement in each 24-hour period. In addition, standard deviations were calculated for each day's day, evening and night period and are presented on each graph. The standard deviations were then averaged over the entire measurement period and are presented in tabular form to show the consistency of the datasets.

\subsection{Case Study A: Rural location near A12}

Case Study A was a typical tranquil rural location separated by $1.4 \mathrm{~km}$ of flat fields from the nearest noise source - a major arterial road, A12, and railway line to London, see Figure 3. Measurements were taken over 1 week $29^{\text {th }}$ May to $4^{\text {th }}$ June 2020. Figures 4-6 show the noise levels for the day, evening and night measurements.

By comparing LAeq, LA10 and LA90 values in Figures 4-5, an unusual result was seen in that the LAeq which was found to be approximately the same as the LA10 value for the day and evening periods. This would indicate that transportation noise was not dominant. This hypothesis was further strengthened by the results shown in Figure 6, night-time, where the LAeq was higher than the median LA10 value. This would not normally be possible except if the noise levels were very stable but there were a very few very noisy events.

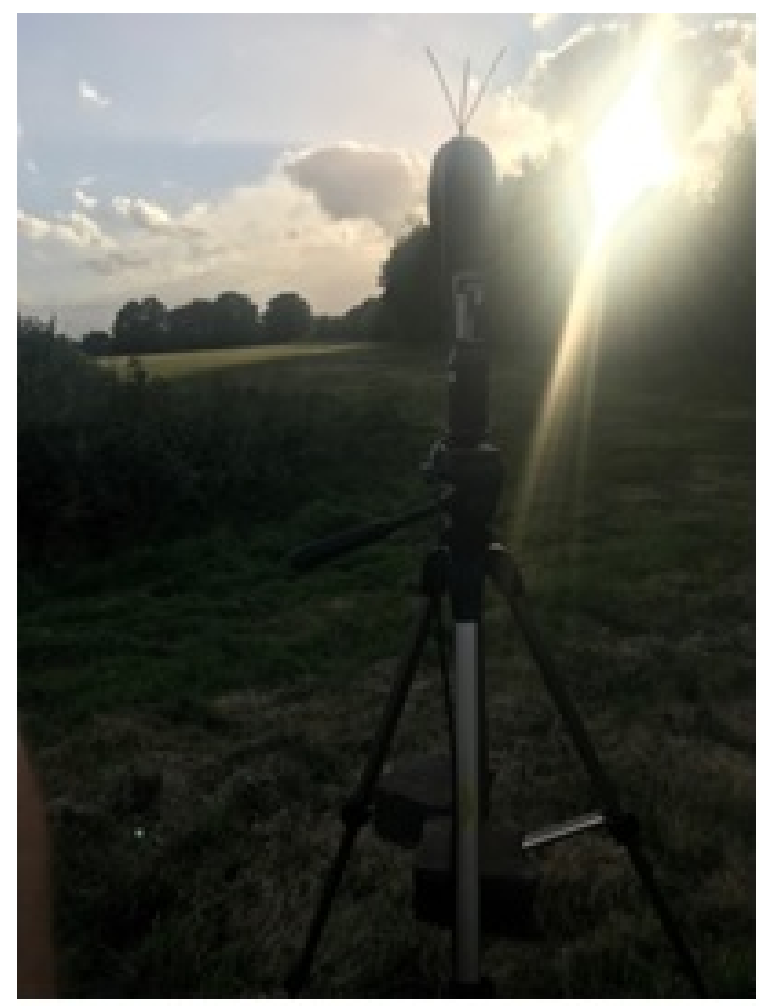

Figure 3: Rurally located monitor station, Case Study A

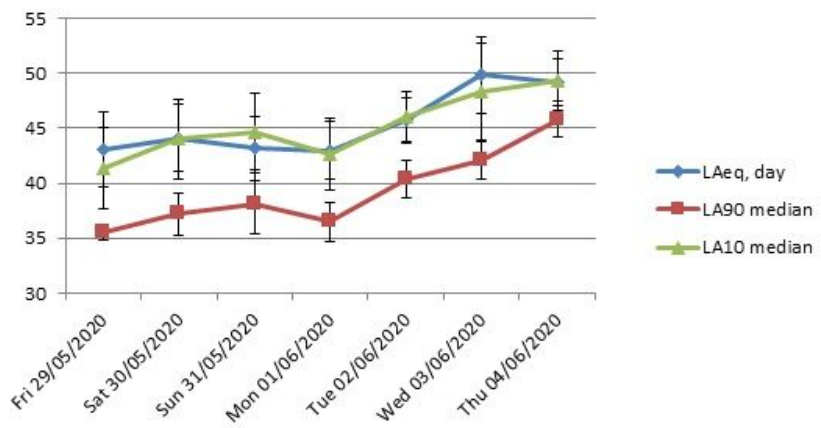

Figure 4: Case Study A: Day-time noise levels +/-1 standard deviation

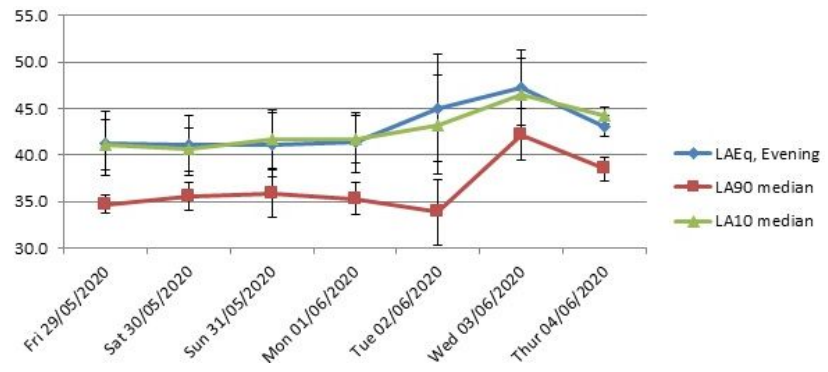

Figure 5: Case Study A: Evening noise levels +/-1 standard deviation 


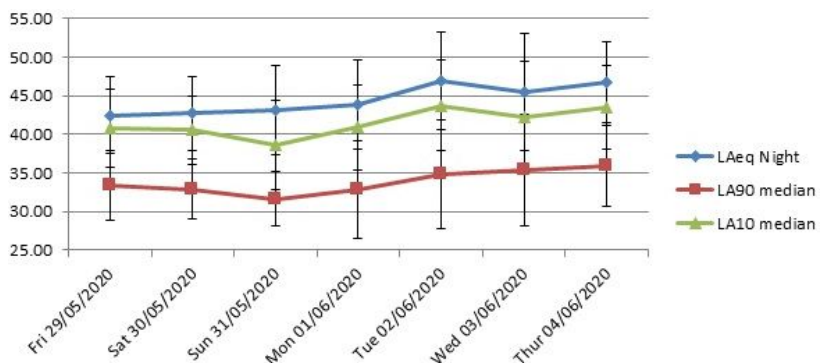

Figure 6: Case Study A: Night-time noise levels +/-1 standard deviation

By analyzing the data over the week when the schools reopened a consistent increase in noise levels can be clearly seen, Figures 4-6, for the day, evening, and night periods. This has been tabulated in Table 2 based on first and last measured noise levels.

Table 2: Shows the increase in noise levels and the standard deviation in the measurement for Case Study A - a rural location over the week when the schools partially reopened

\begin{tabular}{cccc}
\hline & LAeq $(\mathrm{dB})$ & LA90 $(\mathrm{dB})$ & LA10 $(\mathrm{dB})$ \\
\hline Day & $6.0 \sigma=2.8$ & $10.2 \sigma=1.7$ & $8.0 \sigma=3.3$ \\
Evening & $1.9 \sigma=3.5$ & $3.8 \sigma=2.1$ & $3.0 \sigma=3.0$ \\
Night & $4.2 \sigma=5.8$ & $2.5 \sigma=5.4$ & $2.7 \sigma=5.6$ \\
\hline
\end{tabular}

Looking at Table 2 most activity change occurred during the day, a $6.0 \mathrm{~dB}$ increase, whilst the evening noise levels showed the smallest increase, $1.9 \mathrm{dBA}$. This would follow the government recovery plan of opening up for day time activity but with very little open in the evening e.g. no sporting events, pubs or restaurants. The analysis is further strengthened when inspecting figure 4 and 6 - day and night-time noise levels at the weekend saw a dip probably caused by reduced freight traffic, confirmed by the traffic flow data [16]. The night-time noise measurement had the largest inconsistency with a standard deviation of approximately $5 \mathrm{~dB}$ for all parameters. The LA90 was the most consistency parameter, which was as expected, for a rural location, as activity is limited.

\subsection{Case Study B: Trunk road location very near A120}

Case Study B was adjacent to a busy trunk road, A120, with the sound meter positioned at the side of the road, $25 \mathrm{~m}$ distance from the centre line. The A120 is the main EastWest road so does not go to London but goes from a Ferry
Port across to London Stansted airport. The primary sound source was again road traffic, see Figure 7. Measurements were taken over 6 days, 7-12 ${ }^{\text {th }}$ June 2020 the very end of the English lockdown. Figures 8-10 show the noise levels for the day, evening and night measurements.

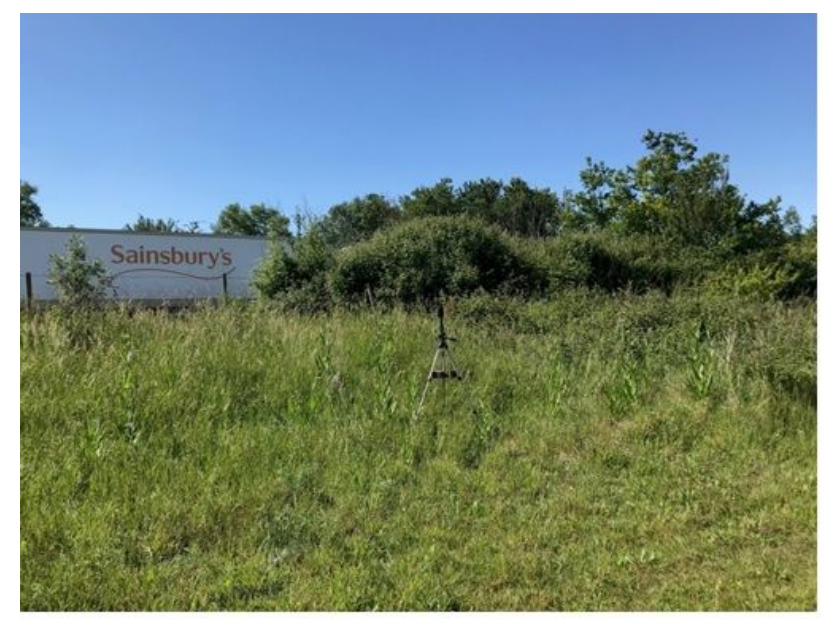

Figure 7: Shows a rurally located monitoring station, Case Study B, next to a major trunk road

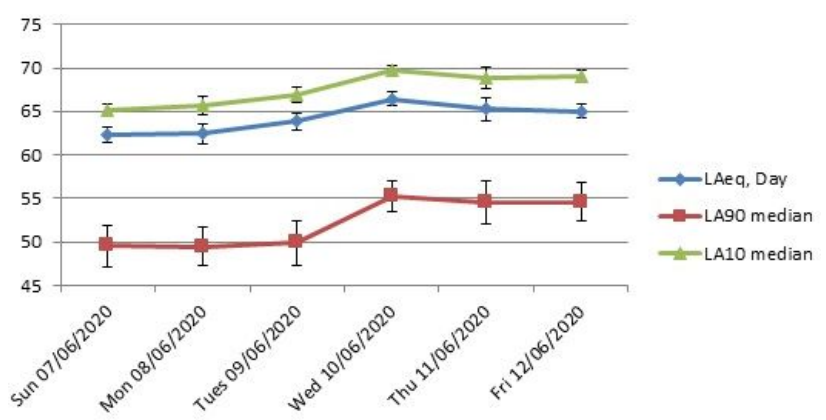

Figure 8: Case Study B: Daytime noise levels +/-1 standard deviation

By comparing LAeq, LA10 and LA90 values in Figures 8-10, a more consistent result between the parameters was seen compared to Case Study A. A difference of approximately $3 \mathrm{~dB}$ between LAeq and LA10 was clear. This agrees with the research of Abbott and Nelson finding that $\mathrm{L}_{A 10,18 \text { hour }}$ can be adjusted to LAeq, by a $3 \mathrm{~dB}$ reduction, for heavily used roads in the UK [19].

By analyzing the data over the working week, ignoring the Sunday data, the very end of full lockdown was captured. The continuing increase in activity was consistent with the increase in noise levels, see Figures $8-10$. This has been tabulated in Table 3. 


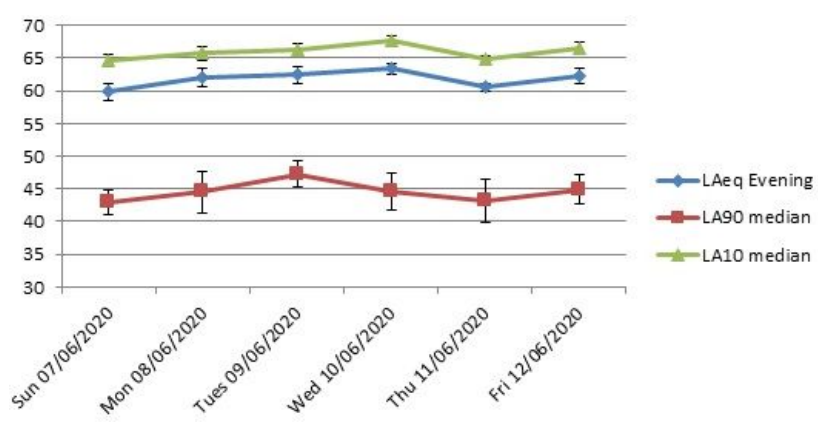

Figure 9: Case Study B: Evening noise levels $+/-1$ standard deviation

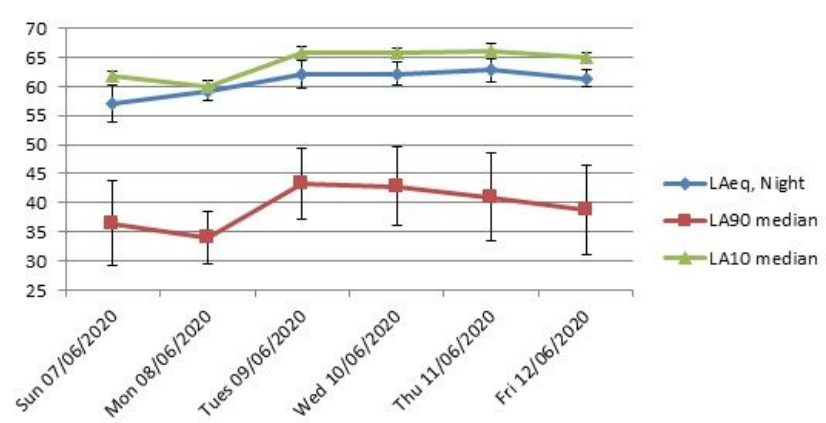

Figure 10: Case Study B: Night-time noise levels +/-1 standard deviation

Table 3: Shows the increase in noise levels over the working week and the standard deviation of the measurements for Case Study B adjacent to a busy road at the end of lockdown

\begin{tabular}{cccc}
\hline & LAeq $(\mathrm{dB})$ & LA90 $(\mathrm{dB})$ & LA10 $(\mathrm{dB})$ \\
\hline Day & $2.5 \sigma=1.0$ & $4.9 \sigma=2.3$ & $3.5 \sigma=0.9$ \\
Evening & $0.4 \sigma=1.1$ & $0.4 \sigma=2.6$ & $0.8 \sigma=0.8$ \\
Night & $2.1 \sigma=2.1$ & $4.9 \sigma=6.6$ & $5,1 \sigma=0.9$ \\
\hline
\end{tabular}

Looking at Table 3 all noise parameters increased over the working week. As for Case Study 1, during the day, the background noise condition increased by the greatest amount, $4.9 \mathrm{dBA}$, demonstrating consistent increased activity. The evening noise parameters only increased by a tiny amount, 0.4-0.8 dBA, demonstrating a lack of available activities at this time, in line with government policy. The 2.5 $\mathrm{dB}$ increase in daytime noise levels would indicate a near doubling of traffic flow which was in line with the increase in the primary noise source, heavy goods vehicles, see arrows on Figure 11 [16]. The analysis is further strengthened when inspecting Figures 8-10 - daytime and night-time noise levels where a Sunday dip is seen in noise levels due to freight traffic being reduced, see Figure 11.

The consistency of the LA10 measurements was extremely high, $\sigma<0.9 \mathrm{~dB}$, see Table 3 . This was expected for

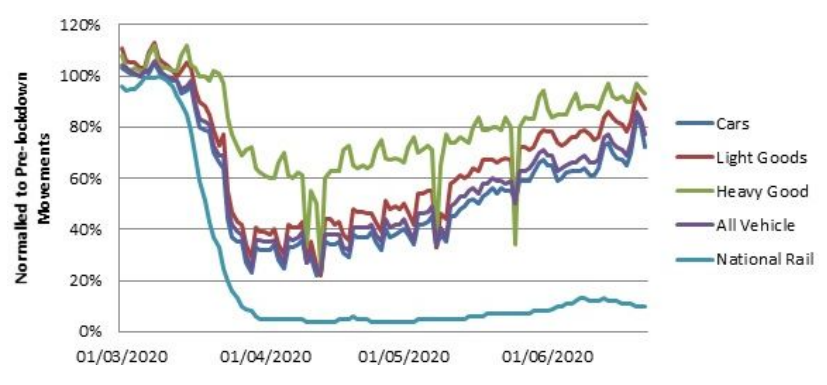

Figure 11

measurement next to a busy arterial road and demonstrates the value of this little used acoustic parameter (outside of the UK) compared to LAeq. The LA90 parameter was the by far the most inconsistent. This was particularly apparent for the night-time measurements. This could be explained by 6-7am being part of the night-time measurement, when this is now the start of rush hour and hence noise levels greatly increased creating the inconsistency in the dataset. Abbott and Nelson [19] noted that LA10 is normally measured from 06:00-12:00 midnight as part of CRTN.

\subsection{Analysis}

Comparing the two case studies, both located near national roads, it is very clear that although only $5 \mathrm{~km}$ separate the two case study locations the measurements were very different, Case Study A $\mathrm{L}_{\text {day }}$ 43-50 dBA and Case Study B $\mathrm{L}_{\text {day }}$ 62-65 dBA. However, they both showed an increase in noise levels with the increase in transport activity, see Figure 11.

This was further analysed using recently released locally recorded traffic data [20] at the vehicle counting stations nearest to the measurement locations on the roads of interest: A12 and A120, see Figure 12. The traffic flow data was also recorded every 15 minutes starting on the hour and therefore matches the sound measurement methodology outlined in Section 3. For completeness, the same traffic monitoring station data for 2019 is also given in Figure 12.

Studying the local traffic data over the full lockdown period, see Figure 12, road traffic rose from 14210 vehicles on the A12 on Monday $24^{\text {th }}$ March 2020 to 23380 on Tuesday $30^{\text {th }}$ June, a rise of $64.5 \%$. Comparing this to the first Tuesday in March, $3^{\text {rd }}$ March 2020, the vehicle movements were counted as 30110 which is double the initial lockdown value. The lowest traffic flows were recorded on Sunday $29^{\text {th }}$ March 2020 at 3200 vehicle movements, thus confirming the nationally collected data that Sunday had the lowest number of traffic movements, which was heavily influenced by the lack of freight vehicles, see Figure 11. 
In contrast he A120 the traffic also rose from lockdown 12919 vehicle movement on $24^{\text {th }}$ March 2020 to 18567 on $30^{\text {th }}$ June 2020, a rise of $43.7 \%$. On the $3^{\text {rd }}$ March 2020, the traffic flow was measured at 26505 vehicles, again over double that on the day of lockdown. The lowest traffic flow was again recorded on Sunday $29^{\text {th }}$ March 2020 at 3151 vehicle movements. Further confirming that freight traffic was massively reduced on the roads.

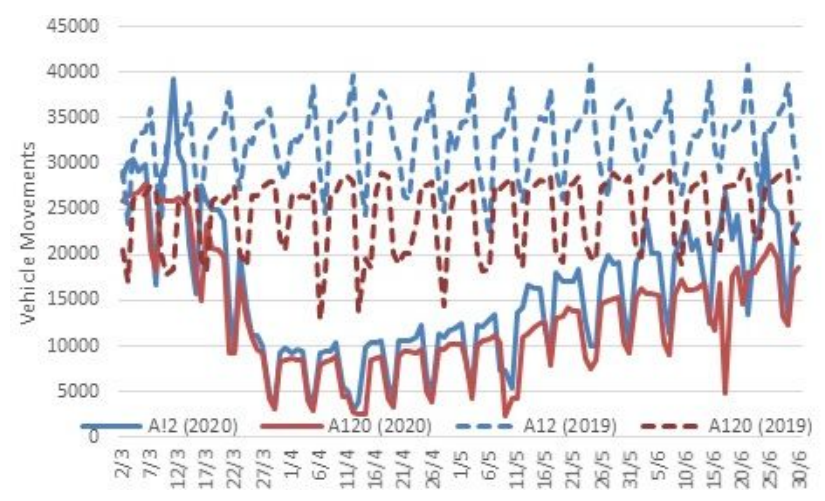

Figure 12: Local daily vehicle movements over the lockdown period and the same period the previous year for the two case studies [20]

The increase in noise levels $2.5 \mathrm{dBA}$ in the daytime LAeq exactly matched the expected increase in road traffic (16319 vs 9115) over the working week for Case Study B - the A120. However, for Case Study A the traffic flow was steady (19150 vs 20230) for the week, a marginal increase, however the measured daytime LAeq noise levels increased by 6 dBA. This indicated that there were other sound sources not related to road traffic influencing the result. As such, noise measurements should only be taken where there is an identifiable primary sound source.

Looking at the difference in LAeq values between the two locations over the measurement period, a consistent 15-20 dB difference was found in the day (Figures 4 and 8), evening (Figures 5 and 9), and night-time (Figure 6 and 10) noise levels was found. In terms of the background noise levels, LA90, Case Study B was $10 \mathrm{~dB}$ higher during the day, $5 \mathrm{~dB}$ during the evening and $5 \mathrm{~dB}$ higher overnight. These results could be used to help define tranquillity, for which Case Study A is a fine example.

To clarify the data shown in Figure 12, the 7-day rolling average for vehicle movements during March-June was calculated both for Lockdown and in the previous year, see Figure 13. A clear dip in vehicle movements can be seen in the 2020 data one week before Lockdown formally commenced. Comparing the 2019 and 2020 data Figure 13 clearly shows that vehicle movements were similar in early March and

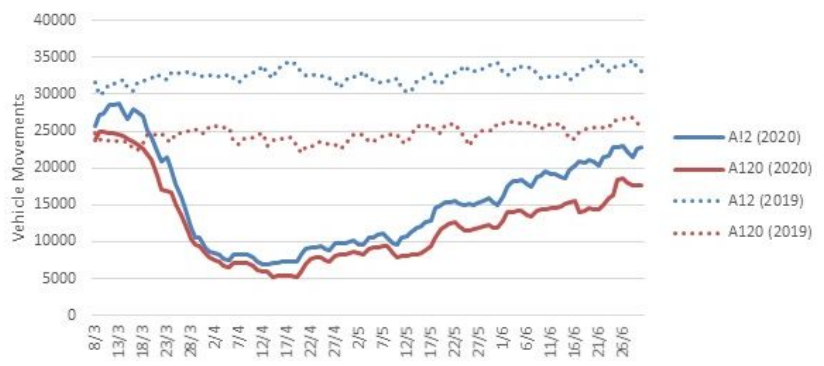

Figure 13: The 7-day rolling average of local daily vehicle movements over the Lockdown period and the same period the previous year for the two case studies [20]

have slowly rebounded over Lockdown for both the A12 and the A120 data.

The Lockdown decline was found to be deeper and more rapid in the A12 dataset, a major highway to London compared to the A120 data, the east-west route. The recovery can be seen to have reached $70 \%$ of the previous year's vehicle movement in the case of the A120 and 67\% in the case of the A12 by the end of June 2020. The national data, Figure 11, shows an approximate $80 \%$ recovery in road traffic which indicates that around London the effect of Lockdown was greater with people likely switching to on-line working and socialising methods.

\section{Preliminary conclusions and further work}

The work presented here was largely focused on the creation of the Quiet Project, the reasoning behind the chosen environmental noise methodology (quality vs quantity), the measurement and soundscape templates and the outreach work. In addition, two case studies were present to illustrate how raw data should be processed and analysed against traffic flow data to establish how the sound environment changed during the first lockdown.

The longitudinal measurements showed how government policy affect the environmental noise, illustrated by the greatest easing of lockdown, the schools reopening, with the day-time levels increasing the most over the working week, whilst a minimal increase was found in the evening measurements. An unusual result was found in the drop in noise levels on Sunday matching a significant reduction in freight movement.

The two case studies were located near each other but had completely different primary noise sources. The results of the longitudinal measurements could be used to define 
tranquillity with a 15-20 dB difference between the noise parameters for day, evening, and night periods.

One unforeseen issue was the slow response from the contacted large infrastructure organisations. This was caused by the lack of staff due to the furlough scheme. This should be rectified by late 2020 when data and staff will both be available to upload the noise measurements from their respective permanent monitoring systems.

The future aim of the Quiet Project is to become the world's first annual national survey of environmental noise levels and Soundscape observations. The project will be used to create on-line content for school children, as well as create public engagement opportunities. This has already started with a newspaper article, "Silence is Golden" [21].

In the longer term the databank will inform future multi-disciplinary research in areas such as ecology and animal behaviour, transport and planning, health and wellbeing, and air quality. This will require social surveys and more analysis using objective data sourced from different disciplines.

Here are five possible examples of future application for the dataset beyond creating a baseline for environmental noise. Example 1: tracking economic recovery through comparative analysis of traffic flows and Air Quality Management Areas. Example 2: provide insight for Soundscape and Air Quality consultation on TAN 11 [22]. Example 3: Health and Wellbeing of Wales based on noise complaints from the Noise App [23]. Example 4: the effect of the change in the sound environmental around airports using Civil Aviation Authority data [24]. Example 5: to assess the UK wide COVID-19 noise environment against the new WHO community noise guidance $[25,26]$.

New areas of research are possible for instance, data mining the databank to determine overflight noise levels from high attitude jets which would normally not be identifiable, based on identified tranquil areas and flight corridors. The databank could also be used to greater understand the effect of metrological conditions on noise measurements to validate sound propagation models.

Finally, the Quiet Project has identified a need for a network of permanent monitoring stations. This would be like that used to count traffic on major roads and motorways across the UK, or the seismic acoustic network. This would be of great benefit to the nation for the study of the effect on people of environmental noise and soundscape, and to establish the value of quiet.

To organise this new resource, it would be advisable to create a virtual national noise network by linking the current and any future networks together. In fact, to improve upon the traffic flow data system, it is recommended that the national noise monitoring system would use wireless technology to allow the data to be analysed centrally in real-time, rather than having data posted to a website 6 weeks after collection.

Acknowledgement: The authors acknowledge the support of the Institute of Acoustic, Association of Noise Consultants, the Noise Abatement Society, EPSRC funded UK Acoustics Network (UKAN) EP/R005001/1 and KSG Acoustics. We extend thanks to ANV Measurement Systems and Campbell Associates for supplying acoustic instrumentation, and to all the participants who so kindly volunteered their time and resources.

Conflict of Interests: The authors declare no conflict of interest regarding the publication of this paper.

\section{References}

[1] Manvell D, Ballarin Marcos L, Stapelfeldt H, Sanz R. SADMAM Combining Measurements and Calculations to Map Noise in Madrid, Proc [Prague, Czech Republic.]. Inter-Noise. 2004 Aug;2004:22-5.

[2] Benocci R, Bellucci P, Peruzzi L, Bisceglie A, Angelini F, Confalonieri C, et al. Dynamic Noise Mapping in the Suburban Area of Rome. Environments. 2019;6(7):79-87.

[3] Coensel B, Sun K, Wei W, Van Renterghem T, Sineau M, Ribeiro C, et al. Dynamic noise mapping based on fixed and mobile sound measurements [Maastricht.]. Proc. Euronoise. 2015 Jun;2015:1-3.

[4] Benocci R, Molteni A, Cambiaghi M, Angelini F, Roman H, Zambon G. Reliability of Dynamap traffic noise prediction. Appl Acoust. 2019;156:142-50.

[5] Wei W, Van Renterghem T, De Coensel B, Botteldooren D. Dynamic noise mapping: A map-based interpolation between noise measurements with high temporal resolution. Appl Acoust. 2016;101:127-40.

[6] www.thequietproject.co.uk

[7] www.ioa.org.uk

[8] www.association-of-noise-consultants.co.uk

[9] www.noiseabatementsociety.com

[10] www.acoustic.ac.uk

[11] www.soundprint.io

[12] Lincoln J. www.acoustics.ac.uk/resources/impact-of-covid-19-r estrictions-on-the-uk-acoustics-industry-provisional-surveyres ults-by-dr-john-lincoln [accessed 15 September 2020].

[13] IEC 61672-1:2013 Electroacoustics: Sound level meters- Part 1 Specification.

[14] BS7445 -1:2003 Description and measurement of environmental noise.

[15] https://www.nhm.ac.uk/discover/nature-liberated-by-lockdow n.html [accessed 5 November 2020].

[16] www.gov.uk/government/statistics/transport-use-during-the coronavirus-covid-19-pandemic [accessed 22 June 2020].

[17] BS4142:2014 Methods of rating and assessing industrial and commercial sound. 
[18] ISO/TS 12913-2: 2018 Acoustics - Soundscape Part 2 Data collection and reporting requirements, Zurich, Switzerland.

[19] Abbott P, Nelson P. Converting the UK traffic noise index LA10, $18 \mathrm{~h}$ to EU noise indices for Noise Mapping. TRL Limited; 2002.

[20] http://tris.highwaysengland.co.uk/detail/traflcflowdata [accessed 2 September 2020]

[21] https://www.theguardian.com/science/2020/jun/20/why-loc kdown-silence-was-golden-for-science [accessed 5 November 2020]

[22] Air Quality and Soundscape a review of TAN 11 https://gov. wales/air-quality-and-soundscape-review-tan-11
[23] App N. RH Environmental Ltd https://www.digitalmarketpla ce.service.gov.uk/g-cloud/services/983852095456839

[24] Civil Aviation Authority https://www.caa.co.uk/Data-and-an alysis/Airspace-and-environment/Environment

[25] Guidelines to Community Noise, World Health Organisation. 1999.

[26] Night Noise Guidance for Europe, World Health Organisation. 2009. 